\title{
AVALIAÇÃO DE PARÂMETROS DE QUALIDADE EM AGUARDENTES DE CANA PRODUZIDAS NO ESTADO DA PARAÍBA
}

\author{
ANA KATARINA DOS SANTOS LIMA * \\ IAN CARNEIRO DA CUNHA NÓBREGA **
}

\begin{abstract}
Parâmetros de qualidade de 10 marcas comerciais de aguardente de cana, produzidas no Estado da Paraíba, foram avaliados tendo como referenciais os padrões estabelecidos pelo Ministério da Agricultura brasileiro (graduação alcoólica, acidez volátil e cobre). Apenas duas marcas de aguardente de cana apresentaram graduação alcoólica de acordo com os valores especificados nos rótulos. Todas as marcas analisadas enquadraram-se nos padrões de acidez volátil, embora uma tenha apresentado valor relativamente elevado. $A$ concentração de cobre na mesma amostra superou em $70 \%$ o limite tolerado pela legislação $(5 \mathrm{mg} / \mathrm{L})$, sugerindo que a alta acidez volátil contribuiu para maior arraste de cobre para o destilado. Nas demais marcas, a concentração média de cobre foi de $2,5 \mathrm{mg} / \mathrm{L}$. Verificouse a necessidade de implantação de melhoria nos sistemas de controle internos das destilarias para que os produtos atendam os padrões estabelecidos pela legislação.
\end{abstract}

PALAVRAS-CHAVE: AGUARDENTE DE CANA-ACIDEZ VOLÁTIL; AGUARDENTE DE CANA-COBRE; AGUARDENTE DE CANA-GRADUAÇÃO ALCOÓLICA.

\section{INTRODUÇÃO}

A agroindústria da cana-de-açúcar brasileira está fundamentada, principalmente, na produção de álcool, açúcar, aguardente (cachaça) e rapadura. A cachaça, bebida fermento-destilada com teor alcoólico entre 38 e 54\% (BRASIL, 1997), é normalmente processada na forma

* Bolsista, Programa Institucional de Bolsas de Iniciação Científica - CNPq/ Universidade Federal da Paraíba (UFPB).

** Ph.D. em Ciência de Alimentos, Professor Adjunto do Departamento de Tecnologia Rural, UFPB, Bananeiras, PB, Brasil (e-mail: ian.nobrega@uol.com.br). 
industrial ou artesanal. O processo produtivo industrial é realizado em grandes empresas e as cachaças obtidas apresentam padrão relativamente uniforme de qualidade. No processo artesanal, as cachaças são elaboradas em pequena escala de acordo com as tradições. Geralmente, o produto é obtido por meio de fermentação alcoólica "natural" (uso de culturas de leveduras selvagens obtidas in loco) e destilação em alambiques de cobre.

De acordo com a Associação Brasileira de Bebidas são lançadas no mercado anualmente cerca de 1,5 bilhões de litros de cachaça, tornando-a uma das bebidas alcoólicas destiladas mais produzidas no mundo. A Paraiba tem se posicionado em oitavo lugar no ranking nacional de produção, sendo ultrapassada pelos estados de São Paulo, Pernambuco, Ceará e Rio de Janeiro (nos quais estão localizadas as grandes indústrias). O Estado da Paraíba, que tem como característica a forte segmentação do setor aguardenteiro em micro e pequenas destilarias, destaca-se entre os principais produtores de cachaça artesanal (COUTINHO, 2001).

Desde 1993, mediante articulações e parcerias com diversos órgãos públicos e privados, o Governo do Estado da Paraíba vem implementado programas para o desenvolvimento e consolidação da agroindústria de aguardente. A partir de 1997 foi iniciado o Projeto de Modernização do Setor Sucroalcooleiro, como parte do Programa de Modernização e Competitividade dos Setores Econômicos Tradicionais, ampliando parcerias e possibilitando novas ações nesse campo (ESTADO DA PARAÍBA, 2000; ESTADO DA PARAÍBA, 2002). No entanto, a implementação desses programas não resultou em estudos e publicações sobre a qualidade físico-química da aguardente de cana produzida no Estado da Paraíba, ou sua adequação à legislação pertinente. Entende-se que estudos sobre a qualidade da aguardente, aliados aos de ordem econômica, servirão para traçar políticas mais eficientes para o desenvolvimento e melhoramento da agroindústria de aguardente no Estado.

A qualidade físico-química da aguardente de cana no Brasil é regulamentada pelo Ministério da Agricultura (BRASIL, 1997), que estabelece limites para diversos parâmetros (graduação alcoólica, acidez volátil, ésteres, alcóois superiores, aldeídos, furfural, metanol e cobre). Pesquisas realizadas por VARGAS e GLORIA (1995) e SILVA 
e NOBREGA (2001) mostraram que a acidez volátil e o teor de cobre (com implicações consideráveis no campo sensorial e toxicológico das aguardentes) são os parâmetros mais comumente envolvidos na transgreção da legislação vigente.

O objetivo deste trabalho foi avaliar a qualidade de dez importantes marcas de aguardentes de cana, produzidas no Estado da Paraíba, mediante os seguintes parâmetros: cobre, acidez volátil (em ácido acético) e etanol (graduação alcoólica).

\section{MATERIAL E MÉTODOS}

\subsection{AGUARDENTES DE CANA}

Foram adquiridas 3 amostras (garrafas de $600 \mathrm{~mL}$ ou $1 \mathrm{~L}$ ) de 10 diferentes marcas comerciais de aguardente de cana no comércio paraibano (3 repetições por marca), entre o período de agosto e novembro de 2001. A seleção das marcas de aguardente, todas de aspecto incolor, foi baseada em suas notórias relevâncias comerciais ou tradição (Quadro 1).

\section{QUADRO 1 - INFORMAÇÕES GERAIS SOBRE AS AGUARDENTES DE CANA SELECIONADAS PARA A PESQUISA}

\begin{tabular}{|c|c|c|}
\hline $\begin{array}{c}\text { Marca da aguardente } \\
\text { (constante no } \mathbf{r} \text { tulo) }\end{array}$ & $\begin{array}{c}\text { Caracteriza o do } \\
\text { processo de fabrica a o }\end{array}$ & $\begin{array}{c}\text { Munic pio de produ a o } \\
\text { na Para ba }\end{array}$ \\
\hline Anel do Brejo & sem informa ${ }^{a}$ o & Alagoa Nova \\
\hline Caranguejo & industrial & Campina Grande \\
\hline Caru $\propto$ & artesanal & Sobrado \\
\hline Maribondo & artesanal & Guarabira \\
\hline Rainha & artesanal & Bananeiras \\
\hline S o Paulo & industrial & Cruz do Esp rito Santo \\
\hline Serra Limpa & artesanal & Duas Estradas \\
\hline Tambaba & artesanal & Conde \\
\hline Triunfo & artesanal & Areia \\
\hline Volopia & artesanal & Alagoa Grande \\
\hline
\end{tabular}

As determinações das concentrações de cobre nas aguardentes foram realizadas no Laboratório de Compostos de Coordenação e Química de Superfície (LCCQS), do Centro de Ciências Exatas e da Natureza da Universidade Federal da Paraíba (UFPB), durante o período de 
agosto de 2002. As determinações de grau alcoólico real e acidez volátil foram efetuadas no Laboratório de Tecnologia da Cachaça (LATEC) do Centro de Formação de Tecnólogos da UFPB, entre o período de janeiro e maio de 2002 . Todas as análises foram realizadas em duplicata.

\subsection{GRAU ALCOÓLICO REAL}

Determinou-se o grau alcoólico real do destilado alcoólico da aguardente mediante alcoômetro Gay Lussac (escala de 0 a $100^{\circ} \mathrm{GL}$ ), provido com termômetro e aferido a $20^{\circ} \mathrm{C}$, conforme metodologia do INSTITUTO ADOLFOLUTZ(1985).

\subsection{ACIDEZ VOLÁTIL EM ÁCIDO ACÉTICO}

A acidez volátil em ácido acético do destilado da aguardente foi determinada por titulometria com $\mathrm{NaOH}$ (INSTITUTO ADOLFO LUTZ, 1985).

\subsection{COBRE}

Para as determinações das concentrações de cobre nas amostras de aguardente usou-se espectrofotômetro de absorção atômica, marca GBC (GBC Scientific Equipment Pty Ltd., Australia), modelo 908AA, com chama de ar-acetileno e lâmpada de catôdo oco, a 324,8 nm. Antes da análise das amostras construiu-se curva-padrão de cobre (sulfato de cobre pentahidratado, Aldrich) em matriz etanólica a 40\% v/v para calibração do equipamento.

\section{RESULTADOS E DISCUSSÃO}

A média dos resultados das análises de cada uma das 3 amostras de 10 marcas de aguardente consta da Tabela 1. Os resultados também são apresentados em médias e desvios-padrões de forma a melhor comparar os resultados de cada marca com os padrões estabelecidos pela legislação vigente. 


\section{TABELA 1 - GRADUAÇÃO ALCOÓLICA REAL (\% VOLUME/ VOLUME A $20 \stackrel{\circ}{\circ} \mathrm{C})$, ACIDEZ VOLÁTIL EM ÁCIDO ACÉTICO $(\mathrm{mg} / 100 \mathrm{~mL}$ DE ÁLCOOL ANIDRO DA AGUARDENTE) E TEOR DE COBRE (mg/L DE AGUARDENTE) DE AMOSTRAS DE AGUARDENTE DE CANA PRODUZIDAS NO ESTADO DA PARAÍBA}

\begin{tabular}{|c|c|c|c|c|c|}
\hline \multirow[t]{2}{*}{ Marca } & \multirow[t]{2}{*}{ Amostra $^{1}$} & \multicolumn{2}{|c|}{ Gradua ${ }^{a}$ o Alco lica } & \multirow{2}{*}{$\begin{array}{l}\text { Acidez } \\
\text { Vol/AFil }\end{array}$} & \multirow[t]{2}{*}{ Cobre } \\
\hline & & $\mathrm{R}$ tulo $^{3}$ & Real & & \\
\hline \multirow{4}{*}{ Anel do Brejo } & 1 & \multirow{3}{*}{52,3} & 44,0 & 91,2 & 8,1 \\
\hline & 2 & & 43,0 & 83,1 & 8,7 \\
\hline & 3 & & 44,0 & 80,2 & 8,7 \\
\hline & \multicolumn{2}{|c|}{ Mødia $(D P)^{2}$} & $43,3(0,6)$ & $84,8(5,7)$ & $8,5(0,3)$ \\
\hline \multirow{4}{*}{ Caranguejo } & 1 & \multirow{3}{*}{39} & 40,0 & 18,7 & 1,7 \\
\hline & 2 & & 38,0 & 11,7 & 1,3 \\
\hline & 3 & & 39,0 & 11,7 & 0,7 \\
\hline & \multicolumn{2}{|c|}{ MØdia $(D P)^{2}$} & $39,0(1,0)$ & $14,0(4,0)$ & $1,2(0,5)$ \\
\hline \multirow{4}{*}{ Caru $œ$} & 1 & \multirow{3}{*}{42} & 32,0 & 27,0 & 2,7 \\
\hline & 2 & & 39,0 & 14,0 & 2,8 \\
\hline & 3 & & 40,0 & 13,0 & 2,7 \\
\hline & \multicolumn{2}{|c|}{ MØdia $(D P)^{2}$} & $37,0(4,4)$ & $18,0(7,8)$ & $2,7(0,1)$ \\
\hline \multirow{4}{*}{$\begin{array}{l}\text { Maribondo (Søie } \\
\text { Prata) }\end{array}$} & 1 & \multirow{3}{*}{42} & 40,0 & 40,2 & 3,6 \\
\hline & 2 & & 40,0 & 19,6 & 3,9 \\
\hline & 3 & & 36,0 & 49,1 & 3,6 \\
\hline & \multicolumn{2}{|c|}{ Mødia $(D P)^{2}$} & $38,7(2,3)$ & $36,3(15,1)$ & $3,7(0,2)$ \\
\hline \multirow{4}{*}{ Rainha } & 1 & \multirow{3}{*}{53} & 48,0 & 8,3 & 2,7 \\
\hline & 2 & & 47,0 & 9,6 & 2,5 \\
\hline & 3 & & 46,0 & 12,2 & 3,0 \\
\hline & $M \varnothing$ & & $47,0(1,0)$ & $10,1(2,0)$ & $2,7(0,3)$ \\
\hline \multirow{4}{*}{ S o Paulo } & 1 & \multirow{3}{*}{42} & 38,0 & 7,0 & 1,3 \\
\hline & 2 & & 39,0 & 7,0 & 1,4 \\
\hline & 3 & & 40,0 & 6,0 & 1,8 \\
\hline & \multicolumn{2}{|c|}{ Mødia $(D P)^{2}$} & $39,0(1,0)$ & $6,7(0,6)$ & $1,5(0,2)$ \\
\hline \multirow{4}{*}{ Serra Limpa } & 1 & \multirow{3}{*}{47} & 44,0 & 17,1 & 2,5 \\
\hline & 2 & & 44,0 & 23,4 & 2,3 \\
\hline & 3 & & 44,0 & 23,0 & 2,8 \\
\hline & $M \varnothing$ & & $44,0(0,0)$ & $21,1(3,5)$ & $2,5(0,2)$ \\
\hline \multirow{4}{*}{ Tambaba } & 1 & & 40,0 & 34,0 & 2,7 \\
\hline & 2 & 45 & 39,0 & 34,0 & 2,8 \\
\hline & 3 & & 40,0 & 23,0 & 2,8 \\
\hline & $M \varnothing$ & & $39,7(0,6)$ & $30,3(6,4)$ & $2,7(0,1)$ \\
\hline & 1 & & 34,0 & 19,0 & 4,0 \\
\hline Triunfo & 2 & 42 & 28,0 & 35,0 & 4,1 \\
\hline & 3 & & 35,0 & 19,0 & 3,9 \\
\hline & $M \varnothing$ & & $32,3(3,8)$ & $24,3(9,2)$ & $4,0(0,1)$ \\
\hline & 1 & & 41,0 & 12,6 & 1,7 \\
\hline Volopia & 2 & 42 & 43,0 & 12,6 & 1,8 \\
\hline & 3 & & 41,0 & 14,0 & 2,0 \\
\hline & $M \varnothing$ & & $42,0(1,2)$ & $13,1(0,8)$ & $1,8(0,2)$ \\
\hline
\end{tabular}

${ }^{1}$ Cada amostra foi representada por uma garrafa de 600 ou $1.000 \mathrm{~mL}$ da aguardente. ${ }^{2}$ Valores médios e desvios- padrões (DP) mostrados entre parênteses nos resultados por marca de aguardente.

${ }^{3}$ Graduações alcoólicas constantes nos rótulos das aguardentes analisadas. 


\subsection{GRADUAÇÃO ALCOÓLICA}

Das 30 amostras analisadas, uma da marca Maribondo (amostra 3) e todas as da marca Triunfo apresentaram graduações alcoólicas inferiores ao padrão estabelecido pela legislação brasileira (BRASIL, 1997). O limite legal mínimo de 38 e máximo de $54 \%$ de etanol v/v a $20^{\circ} \mathrm{C}$ para a concentração de etanol em aguardente é aplicado e aceito em quase todo o mundo como padrão para bebidas alcoólicas destiladas (SILVA e NÓBREGA, 2001). No restante das amostras analisadas, a menor e a maior concentração alcoólica encontrada foram 38 e 48\%, respectivamente (Tabela 1). Metade das amostras analisadas (50\%) situou-se na faixa entre $38-42 \%$ de etanol v/v, $23 \%$ na faixa entre $42-$ $46 \%$.

Em relação à variabilidade dos resultados entre as amostras, expressa pelo desvio-padrão, as marcas Maribondo e Triunfo atingiram os maiores valores. Diferenças entre a concentração alcoólica constante nos rótulos e os valores médios obtidos para cada uma das marcas foram observadas em maior escala nas marcas Triunfo e Anel do Brejo (23,1 e 17,2\%, respectivamente). Outras marcas que ainda mostraram variações relativamente elevadas (em relação ao rótulo) foram Caruçu e Rainha, com 11,9 e 11,3\%, respectivamente. É interessante notar que todas as variações foram negativas, ou seja, os valores encontrados para graduação alcoólica ficaram sempre abaixo do estabelecido no rótulo. Apenas as marcas Caranguejo e Volúpia atenderam, na média, os valores fornecidos pelos seus fabricantes (Tabela 1).

As diferenças observadas (entre a graduação alcoólica real e os valores fornecidos nos rótulos) sugerem que o processo de destilação ou de blendagem (mistura de destilados de diversas graduações alcoólicas) não está sendo realizado de forma apropriada. Para se obter destilados mais uniformes, especialmente a partir de alambique, é importante medir seu teor alcoólico de forma que as frações a serem destiladas ("cabeça", "coração" e "cauda") sejam previamente calculadas. Pequenos ajustes no nível final de etanol da bebida podem ser realizados com base nas regras de diluição, utilizando-se água apropriada ou destilados alcoólicos com menor ou maior concentração em etanol. A adição de água é menos recomendada devido ao risco de turvamento do destilado, que exigirá filtração corretiva posterior. 
A concentração alcoólica da aguardente, impressa pelos próprios fabricantes nos rótulos, por respeito ao consumidor e à legislação deve constituir parâmetro de qualidade constantemente monitorado. Sob o ponto de vista sensorial, o etanol constitui um dos componentes voláteis com menor destaque na caracterização do "flavour" das bebidas alcoólicas quando comparado a outros voláteis presentes (BELITZe GROSCH, 1999).

\subsection{ACIDEZ VOLÁTIL}

Todas as 30 amostras analisadas enquadraram-se no padrão estabelecido pela legislação em vigor para acidez volátil (limite de $150 \mathrm{mg}$ de ácido acético por $100 \mathrm{~mL}$ de álcool anidro) (BRASIL, 1997). No entanto, merece destaque o elevado valor encontrado para a marca Anel do Brejo, com média de $85 \mathrm{mg} / 100 \mathrm{~mL}$ de álcool anidro. A marca que apresentou a segunda maior média de acidez volátil foi a Maribondo, cujo valor mostrou-se 2,3 vezes inferior ao observado para a Anel do Brejo (Tabela 1).

Utilizando as escalas de acidez volátil, sugeridas por SILVA e NÓBREGA (2001), constatou-se que a maioria das amostras analisadas enquadrou-se nos limites de 0-30 (73\% das amostras), de $61-90(17 \%)$ e $31-60$ (10\%) mg de ácido acético/100 mL de álcool anidro. Esses achados sugerem que as aguardentes de cana paraibanas apresentam acidez volátil relativamente baixa. Estudos em maiores escalas, que envolveram aguardentes brasileiras de diversas procedências, apontaram que a acidez volátil da maioria das aguardentes situa-se entre 61-90 mg/100 mL de álcool anidro (SILVA e NÓBREGA, 2001).

Segundo NYKÄNEN e NYKÄNEN (1991), a acidez volátil contribui para o aroma e o sabor das bebidas alcoólicas destiladas. Em trabalhos realizados com diversas marcas de aguardente NASCIMENTO et al. (1998) constataram maior quantidade de ácido acético nas amostras, perfazendo cerca de $90-95 \%$ de todos os ácidos voláteis presentes.

A acidez volátil das aguardentes, no entanto, não pode ser confundida com o caráter excessivamente acético que provoca sensações de ardor na garganta e odor de vinagre. Tal característica pode ser 
proveniente de fermentações alcoólicas bastante contaminadas com bactérias acéticas. Sobre esse aspecto, NÓBREGA (1994) critica o limite de acidez volátil tolerado pela legislação brasileira que permite a comercialização de aguardentes excessivamente ácidas. Estudos que correlacionem os níveis de acidez volátil com a qualidade sensorial da aguardente são necessários para constatar a coerência dos limites de acidez volátil estabelecidos pela legislação brasileira para o produto.

Sob o ponto de vista tecnológico, a acidez das aguardentes pode ser controlada em diversos níveis. Sabe-se, por exemplo, que fermentações alcoólicas conduzidas em boas condições de higiene geram aguardentes com acidez relativamente baixa. Segundo NÓBREGA (1994), os processos naturais de fermentação alcoólica propiciam maiores valores de acidez volátil em comparação com processos fermentativos induzidos por culturas homogêneas de leveduras. Já outros trabalhos evidenciam que o descarte das frações dos destilados alcoólicos denominados "cabeça" e "calda" (especialmente da última) reduz a acidez das aguardentes (BOZA e HORII, 1998; BOZA e HORII, 2000). Entretanto, tal procedimento nem sempre ocorre nas destilarias.

\subsection{COBRE}

Todas as amostras analisadas estavam contaminadas por cobre, confirmando os resultados de diversos autores sobre a ocorrência desse metal nas aguardentes brasileiras há muito tempo (Tabela 1). LUCENA, em 1959, relacionou a presença de cobre na cachaça com a ação dos vapores alcoólicos ácidos nas chapas metálicas de cobre recobertas por carbonato básico de cobre (solúvel em ácidos). No entanto, aguardentes obtidas em destiladores de cobre apresentam característica sensorial melhor que as elaboradas em destiladores fabricados com outros metais. Isso ocorre porque o cobre reduz a acidez, os aldeídos e o teor de enxofre da bebida (FARIA, 1989).

Das 30 amostras analisadas, apenas as da marca Anel do Brejo apresentaram concentrações de cobre acima do limite estabelecido pela legislação brasileira ( $5 \mathrm{mg} / \mathrm{L})$. Nesse caso, a concentração média da marca Anel do Brejo ( $8,5 \mathrm{mg} / \mathrm{L})$ excedeu em $70 \%$ o referido limite. Para o restante das marcas, a concentração média foi de $2,5 \mathrm{mg} / \mathrm{L}$. Tal resultado coincide com os achados de SILVA e NÓBREGA (2001) 
sobre o intervalo de maior incidência de concentração de cobre em aguardentes diversas (2-3 mg/L) (Tabela 1$)$.

A concentração elevada de cobre encontrada para a marca Anel do Brejo pode ter sido causada pela falta de limpeza das chapas internas de cobre do destilador, especialmente, nas serpentinas de condensação (em que os jatos do destilado ácido podem dissolver grande quantidade de carbonato básico de cobre). Essa via de contaminação pode ter sido favorecida pela concentração relativamente alta de acidez volátil das amostras dessa marca, tendo em vista maior solubilidade do carbonato básico de cobre em ácidos.

O cobre é essencial ao metabolismo em níveis de traço. Tanto é que o FOOD AND NUTRITIONAL BOARD (1989) recomenda ingestão diária de cobre entre 1,5 a 3,0 mg/dia para adultos. Estudos sobre a atuação do cobre no organismo revelam sua associação com óxido-redutases dos tecidos e também com a absorção de ferro da dieta para biossíntese de hemoglobina. No entanto, o excesso desse metal pode causar lesões nos vasos capilares, no fígado e nos rins, além de provocar a Doença de Wilson (degeneração hepatolenticular) caracterizada pelo acúmulo de cobre em várias partes do corpo (RICHARDSON, 1993).

\section{CONCLUSÃO}

Apenas $20 \%$ das marcas de aguardente apresentaram concentração média de etanol de acordo com os valores especificados nos rótulos, indicando falhas nos processos de destilação e blendagem dos destilados.

Todas as amostras analisadas enquadraram-se no padrão estabelecido pela legislação brasileira para acidez volátil, sendo que a maioria (73\%) apresentou teores até $30 \mathrm{mg}$ de ácido acético/100 mL de álcool anidro. Portanto, as aguardentes de cana paraibanas apresentaram teores de acidez volátil relativamente baixos, indicando processos fermentativos alcoólicos com baixa contaminação bacteriana.

As amostras de apenas uma marca de aguardente apresentaram concentrações de cobre que excederam o limite tolerado pela legislação. No restante das 9 marcas, a concentração média de cobre 
encontrada foi de $2,5 \mathrm{mg} / \mathrm{L}$. O teor de cobre na aguardente pode ser controlado através de diversos procedimentos, dentre as quais podem ser destacados a limpeza periódica dos destiladores e a separação das frações na destilação (cabeça, coração e calda).

Os problemas constatados em algumas das aguardentes analisadas demandam melhorias nos sistemas de controle internos das destilarias de forma a garantir a qualidade dos produtos, a segurança dos consumidores e a competitividade das empresas.

\section{Abstract}

\section{ASSESSMENT OF QUALITY PARAMETERS OF BRAZILIAN SUGAR CANE SPIRITS PRODUCED IN THE STATE OF PARAIBA}

Quality parameters of 10 commercial brands of sugar cane spirits, produced in the state of Paraíba were evaluated using as references the established parameters by the Brazilian Ministry of Agriculture (alcoholic content, volatile acidity and copper). Only two brands of sugar cane spirits showed the alcoholic concentration in accordance to the values specified on their label. All analyzed brands were within the limits specified for volatile acidity, although one showed relatively high value. The copper concentration in the same sample exceeded $70 \%$ the level tolerated by regulations $(5 \mathrm{mg} / \mathrm{L})$, suggesting that the high volatile acidity contributed for the removal of copper for the distillate. In the other brands, the copper average concentration was of $2.5 \mathrm{mg} / \mathrm{L}$. It was verified the need for an improvement in the internal control systems of the distilleries so that the products assist the standards established by regulations.

KEY-WORDS: SUGAR CANE SPIRIT - VOLATILE ACIDITY; SUGAR CANE SPIRIT - COPPER; SUGAR CANE SPIRIT ALCOHOLIC CONCENTRATION.

\section{REFERÊNCIAS}

1 BELITZ, H.D.; GROSCH, W. Aroma substances. In: BELITZ, H. D.; GROSCH, W. (Eds). Food chemistry. Berlin: Springer-Verlag, 1999. Cap. 5.

2 BOZA, Y.; HORII, J. Influência da destilação sobre a composição e a qualidade sensorial da aguardente de cana-de-açúcar. Ciênc. Tecnol. Aliment., v. 18, n. 4, p. 354-361, 1998.

3 BOZA, Y.; HORII, J. Influência do grau alcoólico e da acidez do destilado sobre o teor de cobre na aguardente de cana. B. CEPPA, v. 18, n. 1, p.85-94, jan./ jun. 2000. 
1997. Regulamenta a Lei no 8.918 de 14 de julho de 1994, que dispõe sobre a padronização, a classificação, o registro, a inspeção, a produção e a fiscalização de bebidas. Diário Oficial [da] República Federativa do Brasil, Brasília, 5 de setembro de 1997.

COUTINHO, E.P. Dinâmica da modernização do setor de produção de aguardente de cana-de-açúcar no Brasil: construindo uma cachaça de qualidade. Rio de Janeiro, 2001. 274 p. Tese (Doutorado) - Coordenação dos Programas de Pós-graduação em Engenharia, Universidade Federal do Rio de Janeiro.

ESTADO DA PARAÍBA. Grupo de Gestão dos Arranjos Produtivos Locais. Caracterização dos arranjos produtivos locais (cana-de-açúcar e ovinocaprinocultura). João Pessoa, 2002. 61 p.

7 ESTADO DA PARAÍBA. Secretaria de Indústria, Comércio, Turismo, Ciência e Tecnologia. Competitividade dos engenhos de cana-de-açúcar do brejo e litoral paraibanos. João Pessoa, 2000. 21 p.

FARIA, J.B. A influência do cobre na qualidade das aguardentes (Saccharum officiarum L.). São Paulo, 1989. 90 p. Tese (Doutorado) Faculdade de Ciências Farmacêuticas, Universidade de São Paulo.

9 FOOD AND NUTRITIONAL BOARD. Recommended dietary allowances. $10^{\text {th }}$ ed. Washington: National Academic, 1989. Cap. 10.

INSTITUTO ADOLFO LUTZ. Normas analíticas do Instituto Adolfo Lutz. 3.ed. São Paulo, 1985. 533 p.

11 LUCENA, V.G. O problema do cobre nas aguardentes. Brasil Açucareiro, v.1, p.33-36, 1959.

NASCIMENTO, R.F.; CARDOSO, D.R.; LIMA NETO, D.S.; FRANCO, D.W. Determination of acids in brazilian sugar cane spirits and other alcoholic beverages by HRGC-SPE. Chromatographia, v.48, n.866, p.757-737, 1998.

13 NÓBREGA, I.C.C. Características de qualidade de aguardentes de cana comerciais e comparação entre dois processos de fermentação. Viçosa, 1994. 67 p. Dissertação (Mestrado) - Departamento de Tecnologia de Alimentos, Universidade Federal de Viçosa.

14 NYKÄNEN, L.; NYKÄNEN, I. Distilled beverages. In: MAARSE, H. Volatile compounds in foods and beverages. New York: Marcel Dekker, 1991. Cap. 15.

15 RICHARDSON, M.L. The dictionary of substances and their effects. Cambridge: Royal Society of Chemistry, 1993. p.407-414.

16 SILVA, P.H.A.; NÓBREGA, I.C.C. Physical-chemical characterization of commercial brands of brazilian sugar cane spirit. MBAA Technical Quarterly, 
v.38, n.3, p.163-166, 2001.

17 VARGAS, E.A.; GLORIA, M.B. Qualidade da aguardente de cana (Saccharum officinarum, L.) produzida, comercializada e/ou engarrafada no Estado de Minas Gerais. Ciênc. Tecnol. Aliment., v. 15, n. 1, p. 43-46, 1995. 